\title{
ON THE MAXIMAL NUMERICAL RANGE OF A HYPONORMAL OPERATOR
}

\section{ABDERRAHIM BAGHDAD AND MOHAMED CHRAIBI KAADOUd}

Abstract. Let $A$ be a bounded linear operator acting on a complex Hilbert space. Let $\sigma(A)$ and $W_{0}(A)$ denote the spectrum and the maximal numerical range of $A$, respectively. In [10], it was shown that if $A$ is a subnormal operator, then

$$
W_{0}(A)=\operatorname{co}(\{\lambda \in \sigma(A):|\lambda|=\|A\|\}),
$$

where $c o($.$) stands for the convex hull of the corresponding set. We extend this result to hyponor-$ mal operators. We give a geometric interpretation of the obtained result and deduce a necessary and sufficient condition to have $0 \in W_{0}(A)$ for a hyponormal operator $A$. Some properties of normaloid operators are also given.

Mathematics subject classification (2010): 47A12, 47A30, 47A63, 47B15, 47B47.

Keywords and phrases: Spectrum, numerical range, maximal numerical range, normal operator, hyponormal operator, normaloid operator.

\section{REFERENCES}

[1] F. F. BONSALL, J. DUNCAN , Numerical ranges of operators on normed spaces and of elements of normed algebras, London Mathematical Society Lecture Note Series 2 Cambridge University Press, London-New York, (1971).

[2] F. F. Bonsall, J. Duncan, Numerical ranges II, London Mathematical Society Lecture Notes Series 10 Cambridge University Press, New York-London, (1973).

[3] L. Fialkow, A note on the operator $X \longrightarrow A X-X B$, Israel. J. Math., 32 (1979), 331-348.

[4] H. L. GAU, K. Z. WANG AND P. Y. WU, Numerical radii for tensor products of operators, Integral Equations Operator Theory, $\mathbf{7 8}$, no. 3, (2014), 375-382.

[5] K. E. Gustafson, D. K. M. RaO, Numerical range: The Field of Values of Linear Operators and Matrices, New York, NY, USA, (1997).

[6] P. R. Halmos, A Hilbert Space Problem Book, Van Nostrand, New York, 1967.

[7] A. N. Hamed, I. M. SPITKOVSKy, On the maximal numerical range of some matrices, Electronic Journal of Linear Algebra, Volume 34 (2018), 288-303.

[8] F. HausdorfF, Der Wertvorrat einer Bilinearform, Math. Z. 3, (1919), 314-316.

[9] B. O. OKello, N. B. OKelo, O. OngAti, On Numerical Range of Maximal Jordan Elementary Operator, International Journal of Modern Science and Technology, Vol. 2, No. 10, (2017) 341-344.

[10] I. M. SPITKOVSKY, A note on the maximal numerical range, Operators and Matrices, to appear.

[11] J. G. Stampfli, Hyponormal operators, Pacific J. Math., 12 (1962), 1453-1458.

[12] J. G. Stampfli, The norm of derivation, Pacific J. Math., 33 (1970), 737-747.

[13] O. Toeplitz, Das algebraische Analogon zu einem Satze von Fejér, Math. Z. 2, no. 1-2, (1918), $187-197$. 